\title{
EXPERIÊNCIAS ESCOLARES DE ESTUDANTES TRANS
}

Tânia Mara Cruz ${ }^{1}$

Tiago Zeferino dos Santos ${ }^{2}$

\section{Resumo}

Este estudo busca resgatar memórias, enquanto estudantes, de duas transexuais femininas, assim autodefinidas, de Tubarão - SC, no intuito de analisar suas experiências escolares durante o paulatino processo de feminilização. Trata-se de pesquisa qualitativa, construída com recortes de histórias de vida na Educação Básica em escolas públicas e nas licenciaturas de História e de Letras em universidades privadas. A pesquisa empírica se deu a partir de entrevistas com roteiro semiestruturado, sendo analisada a partir dos pressupostos dos estudos de gênero e de educação. O contraditório espaço escolar apresentou-se como lugar de discriminação heterossexista, vigilante contra quem não se enquadrasse nos padrões binários e hegemônicos de gênero e de sexualidade. No entanto, devido ao suporte de colegas e da resistência das estudantes trans, tal contexto não as impediu de seguir estudando.

Palavras-chave: Gênero; Sexualidade; Transexualidade; Experiências Escolares

\footnotetext{
${ }^{1}$ Doutora em Educação. Endereço: Av. José Acácio Moreira, n.787, Bairro Dehon, Tubarão, SC, Brasil. CEP 88704-900. Endereço eletrônico: tania.cruz@unisul.br

${ }^{2}$ Mestre em Educação. Endereço: Av. José Acácio Moreira, n.787, Bairro Dehon, Tubarão, SC, Brasil. CEP 88704-900. Endereço eletrônico: thiago.z.santos@ hotmail.com
} 


\section{INTRODUÇÃO}

A partir de um estudo de mestrado sobre as memórias escolares de duas professoras da cidade de Tubarão-SC, que se autodefiniram, no momento da pesquisa em 2013/2014, como transexuais, buscamos conhecer a trajetória e analisar as implicações da presença de estudantes não heterossexuais nas escolas públicas de Educação Básica e na universidade onde ambas estudaram. ${ }^{3}$

A instituição escolar brasileira, apesar da crítica feminista de que a sexualidade não fica do lado de fora dos portões escolares desde os anos de 1980, reluta em promover mudanças, particularmente em relação ao corpo docente e gestor. Uma instituição que, além de contribuir na promoção das desigualdades e hierarquias de classe, também reitera outras hierarquias. Tensões que se tornam mais agudas quando o tema é a presença de estudantes com práticas sexuais e expressões de gênero designados como gays, lésbicas, travestis e transexuais que não se enquadram no modelo hegemônico que implica no alinhamento entre sexo biológico, gênero e heterossexualidade dentro do binarismo de dois sexos, dois gêneros, duas sexualidades: ou seja, homens pelo sexo de nascimento, masculinos e heterossexuais e mulheres pelo sexo de nascimento, femininas e, igualmente, heterossexuais. Todos esses estudantes sofrem o heterossexismo, descrito por Daniel Borrillo (2009) como

\footnotetext{
O padrão com o qual todas as outras sexualidades devem ser comparadas e medidas. É essa qualidade normativa - e o ideal que ela encarna - que constitui uma forma específica de dominação chamada heterossexismo. Este pode ser definido como a crença na existência de uma hierarquia das sexualidades, em que a heterossexualidade assume posição superior. Todas as outras formas são qualificadas, na melhor das hipóteses, como incompletas, acidentais e perversas, e na pior, como patológicas, criminosas, imorais e destruidoras da civilização (BORRILLO, 2009, p. 25).
}

A hierarquia entre modos de vivenciar a sexualidade e gênero, combinada à desvalorização atribuída à feminilidade na sociedade em que vivemos, oferece as bases para a discriminação contra as pessoas trans. Por sua vez, essa compulsoriedade da heterossexualidade é um terreno importante sobre o qual são construídas não só as normas do que pode ou não ser aceito em relação à sexualidade, mas a base para as demais normas em

\footnotetext{
${ }^{3}$ A pesquisa também contemplou as experiências como professoras transexuais e a relação entre estudantes e docentes transexuais, mas tais recortes fogem aos objetivos deste artigo.
} 
que a sexualidade aparece imbricada na sociedade presente na organização familiar, jurídica, escolar ou no campo da saúde, entre outras.

A partir desta problemática, algumas perguntas nortearam nosso roteiro de pesquisa: Como se deram as trajetórias escolares dessas estudantes, inclusive durante suas licenciaturas, em suas experiências de fluidez e de mudanças em relação às suas autodesignações? De que modo ocorreram as discriminações em suas experiências escolares e quais estratégias utilizaram para persistirem e efetuarem o percurso até a conclusão como professoras?

Necessário ressaltar que, se as memórias aqui analisadas são informadas pelo presente, não deixam de contar sobre os mecanismos da construção cotidiana da heteronormatividade presente nos currículos escolares sistematicamente denunciados nas pesquisas de história da educação nas últimas décadas. ${ }^{4}$ Sobre essas histórias escolares e o modo como sexualidade e gênero se apresentaram nesse processo de aprendizagem escolar, falaremos a seguir.

É possível afirmar que as diferentes expressões de masculinidades e feminilidades são personificadas em cada sujeito, independente de seu sexo de nascimento, e resultam de um complexo processo cultural e não de diferenças naturais instaladas em corpos de mulheres e de homens. Não há uma natureza que não seja informada pelo gênero: desde o momento em que se nasce é possível afirmar que o corpo já cresce sob a marca da generificação. $O$ conceito de gênero permite distinguir a dimensão biológica da dimensão cultural ao demonstrar que estas dimensões se cruzam, mas não decorrem uma da outra. Como já afirmou o historiador Thomas Laqueur (2001), a própria ideia de diferença biológica foi produzida no século XIX.

Gênero refere-se, portanto, à construção social de significados de masculinidades e de feminilidades que compõem, em nossa cultura articulados com a sexualidade e em conjunto com outros marcadores sociais - como classe, raça, etnia - os atributos de cada sujeito, e é resultado do modo como cada sociedade se organiza e produz sua cultura. A sexualidade, por sua vez, também não se reduz aos aspectos biológicos, mas comporta os aspectos psicológicos, culturais, sociais e afetivos subjetivamente articulados e, ao mesmo tempo, apoia-se em normas de instituições religiosas, judiciárias, pedagógicas e do campo da saúde. Para Louro,

\footnotetext{
${ }^{4}$ Foge aos objetivos deste artigo cotejar essas memórias (de duas gerações) das estudantes entrevistadas, bem como traçar um panorama histórico do período 1970-2010 sobre o qual são tecidas as narrativas pessoais.
} 
Gênero e sexualidade não são definições seguras e estáveis, mas históricas e cambiantes. Deve-se reconhecer que a maioria das sociedades possui algum tipo de distinção masculino/ feminino e que essa distinção geralmente é relacionada ao corpo. Contudo, isso não quer dizer que os corpos são "lidos" ou compreendidos do mesmo modo em qualquer tempo ou lugar, nem que seja atribuído valor ou importância semelhante às características corporais em distintas culturas (LOURO, 2003, p. 3).

À possibilidade de pensarmos gêneros plurais ou pessoas transgêneros poderíamos agregar a ideia de práticas sexuais e não orientações sexuais, que inevitavelmente amarram o sujeito a uma expressão sexual fixa e a uma essencialização da experiência sexual. Entretanto, observamos que os movimentos sociais $\mathrm{LGBT}^{5}$ no Brasil ainda se organizam por meio de reivindicações identitárias, em um debate que ora se coloca como essencialista, ora como tático nas lutas cotidianas, e que está presente nas narrativas das entrevistadas. ${ }^{6} \mathrm{O}$ processo de luta política também passa pela linguagem e está inserido numa totalidade social que nem sempre torna possível determinadas rupturas, mas essa reflexão foge aos propósitos deste artigo, apesar de a pontuarmos aqui.

A metodologia baseou-se em entrevista com roteiro semiestruturado com cada uma das duas estudantes, já atuantes como professoras em 2013/2014 nas escolas públicas da região de Tubarão-SC quando as entrevistas foram realizadas. De posse da assinatura dos termos de livre consentimento, as entrevistas foram produzidas em separado, com duração de cerca de $2 \mathrm{~h}$ cada, transcritas de modo detalhado pelos próprios pesquisadores, e, posteriormente, submetidas às professoras para autorização de uso e entrega de cópias a elas. Os nomes adotados são fictícios e correspondem ao gênero feminino, conforme o nome social das entrevistadas. A discussão aqui efetuada centra-se, particularmente, em dois recortes das entrevistas: experiências como estudantes da Educação Básica (Ensinos Fundamental e Médio) e experiências como estudantes no Ensino Superior.

A primeira estudante transexual, designada como Jéssica, branca, 25 anos no momento da entrevista, é licenciada em História. Nasceu no Rio Grande do Sul e mudou-se ainda adolescente com sua família para Tubarão - SC, por volta de 2002. Foi nesta mesma cidade que concluiu o Ensino Médio em 2004. No momento da entrevista, trabalhava em uma escola pública estadual como professora de informática. Jéssica graduou-se em História em 2008, e

\footnotetext{
5 A sigla refere-se a Lésbicas, Gays, Travestis, Transexuais e Transgêneros, e é utilizada pelos movimentos. Cabe notar, também, que essa sigla pode aparecer em diferentes formas, e os movimentos utilizam, desde junho de 2008, a forma LGBT, decidida na Conferência Nacional em Brasília (BARBOSA, 2010, p. 1).

${ }^{6}$ Sobre essa discussão ver síntese em Marco Antônio Torres e Marco Aurélio Prado (2014).
} 
desde 2009 trabalhou como professora de História ou de informática, em caráter temporário, em diversas escolas. A outra estudante é Carolina, branca, 49 anos no momento da entrevista e graduada em Letras. Natural de Tubarão - SC, concluiu o Ensino Médio e universitário no final da década 80 nesta mesma cidade. No momento da entrevista era efetiva em uma escola pública estadual de Educação para Jovens e Adultos (EJA), atuando como professora de Língua Portuguesa e Inglesa desde 1996; há muitos anos é militante no movimento LGBT.

As contradições que as experiências transexuais permitem vivenciar, como debateremos a seguir, provocam hostilidades do ambiente escolar, mas eventuais solidariedades, também. Diferentemente de homossexuais - homens masculinos ou mulheres femininas, as pessoas trans se apresentam numa instabilidade de gênero que parece mais provocadora que suas próprias práticas sexuais, talvez por abalarem de modo mais profundo a ideia do binarismo de gênero. Traremos, nas páginas a seguir, um pouco de suas trajetórias permeadas por dúvidas, discriminações e resistências.

\section{A ESCOLA QUE EXCLUI}

O debate sobre sexualidade nas escolas brasileiras ganhou novas dimensões a partir dos movimentos sociais feministas nas décadas de 1970 e 1980, que discutiam a saúde da mulher e suas interfaces com a educação sexual nas escolas. Nos anos seguintes, tal debate articulou-se com a luta contra a epidemia da AIDS e saúde pública. A homossexualidade destacava-se no âmbito das reflexões sobre prevenção à AIDS, uma vez que os homossexuais masculinos, parte devido ao heterossexismo, eram vistos como grupo de risco, apesar da evidente disseminação da doença entre homens ou mulheres heterossexuais.

A partir dos anos 1990, a crescente visibilidade dos movimentos sociais LGBT no Brasil produziu conquistas relativas às políticas públicas, logo abaladas, a partir de 2010, quando se teve um período de conservadorismo que ressurgiu em diferentes instâncias. Dentro desse quadro contraditório, a escola continuou a configurar-se como lugar predominantemente heterossexista, espaço de discriminação e preconceitos, no qual, e em torno do qual, existe um preocupante quadro de violência a que estão submetidos milhões de jovens e adultos LGBT (JUNQUEIRA, 2009). Ademais, embora não seja possível atribuir à escola o poder e a responsabilidade de produzir identidades sociais ou determiná-las de forma 
definitiva, é necessário reconhecer que "suas proposições, suas imposições e proibições fazem sentido, têm 'efeitos de verdade', constituem parte significativa das histórias pessoais" (LOURO, 1999, p. 21).

Dentro da categoria trans, em concordância com Mario Benedetti (2005), podemos considerar todos aqueles que rompem com as fronteiras do sistema binário e o alinhamento corpo-gênero-sexualidade e que se autodefinem como travestis, transexuais e transgêneros. De certo modo, esses sujeitos trans caminham sobre bases movediças, sendo pressionados pela sociedade (e às vezes aceitando essa pressão) no sentido de assumirem uma definição identitária precisa e fixa. Necessário destacar que a definição de transexualidade não é consensual nos espaços por onde circula, como o movimento social ou a academia (TORRES; PRADO, 2014). Por sua vez, as estudantes aqui entrevistadas que se autodefinem como transexuais também são influenciadas por este conjunto de significações e das instabilidades presentes nessas significações.

Entre as diversas narrativas das pessoas trans, é comum nos depararmos com trajetórias semelhantes. Assim como destaca Berenice Bento (2008), pessoas trans são expulsas de casa, impedidas de estudar, de conseguir emprego, e ainda sofrem pressões psicológicas ao solicitar da justiça a mudança de nome e redesignação sexual. Quando travestis ou transexuais sofrem alguma violência, não raro minimiza-se o ato daquele que é considerado justiceiro, já que a ação deste se considera aceitável, tendo em vista que a vítima já é, no senso comum, considerada culpada por transgredir os binarismos. Por fim, observa-se ainda a patologização da transexualidade, que continua alimentando, por meio do senso comum, inclusive do campo da saúde, um significado social de doença mental ou aberração, e como tal, um transtorno que deve ser inspecionado e acompanhado por profissionais, temáticas sempre presentes nas palavras das entrevistadas.

Ao trazermos as experiências na Educação Básica e no Ensino Superior de transexuais femininas que vivenciaram como alunas o período entre 1970 e 2010 (memórias reestruturadas por um olhar adulto e profissional, já como professoras da Educação Básica), pretendemos refletir sobre o significado da escola e da universidade em suas vidas e do sofrimento causado pelo heterossexismo, reafirmado por recentes pesquisas do campo da educação, das quais trazemos alguns dados.

Levantamentos realizados fora do ambiente escolar reafirmam a escola como espaço de discriminações LGBT. De acordo com pesquisa realizada junto a participantes da Parada 
do Orgulho LGBT do Rio de Janeiro, em 2004, a discriminação de caráter homofóbico ${ }^{7}$ nas escolas "assume dimensões de uma epidemia grave quando as vítimas são muito jovens. Nada menos do que 40,4\% dos adolescentes entre 15 e 18 anos foram vítimas dessa experiência. Entre jovens de 19 e 21 anos, 31,3\% referiram-se a discriminações na escola ou na faculdade" (CARRARA; RAMOS, 2005, p. 80).

Visando trazer voz a esses sujeitos, pesquisas têm destacado as narrativas trans nas experiências escolares. William Siqueira Peres (2009) relata algumas cenas vividas por travestis e transexuais femininas ao tratar das memórias escolares: a maioria delas retrata o espaço escolar como uma experiência de rejeição, que termina por ser responsável pelo abandono dos estudos. Este estudo traz depoimento de uma das entrevistadas, Luciana, transexual gaúcha de 28 anos, sobre suas experiências escolares:

\begin{abstract}
Da escola, eu lembro das torturas. Torturas que estavam presentes nos olhares e nos risos que iam desde a servente e a merendeira, passando pelos professores e a diretora, até os colegas de sala e de recreio. Mas o pior mesmo era um guri da minha idade que me perseguia o tempo todo, que me falava grosserias: "Seu veado, vê se cria jeito de homem, seu safado, quando a gente te pegar você vai ver só, você vai aprender a virar homem, vai aprender a parar de ficar com essa mãozinha se requebrando". Quando eu via aquele guri, eu entrava em pânico e pensava: Meu Deus, lá vem aquele Hitler de novo! Enquanto ficava nas ameaças eu aguentava, mas o pior foi quando, ao sair da escola, eu levei uma chuva de pedradas que me machucaram muito e tive que fazer vários curativos. Mesmo assim, eu ainda aguentei muito até terminar a oitava série. Depois disso, nunca mais quis saber de escola (PERES, 2009, p. 252, E. Luciana).
\end{abstract}

Luciana, cuja idade é próxima a uma de nossas entrevistadas quando produziu seu relato, descreveu discriminações na escola semelhantes às histórias de vidas de pessoas trans em ambiente escolar. Uma referência de pesquisa é a de Alessandra Maria Bohm (2009) intitulada Os monstros e a escola: identidade e escolaridade de sujeitos travestis, em que a autora traz à tona diversos quadros comparativos no embate estabelecido entre travestis $e$ instituições escolares. Foram entrevistadas dez travestis, todas do estado do Rio Grande do Sul, a maioria de Porto Alegre e Região Metropolitana. Entre os dados coletados pela pesquisadora e que vem ao encontro de outras pesquisas com pessoas trans, observa-se que $57,4 \%$ delas afirmaram ter sofrido violência verbal por parte de professores e violência física por parte de colegas no mesmo percentual. Outra referência é a pesquisa de Dayana Brunetto Carlin dos Santos (2012), intitulada Cartografias da transexualidade: a experiência escolar $e$

\footnotetext{
${ }^{7}$ Segundo categorização da pesquisa.
} 
outras tramas, cuja intenção foi evidenciar memórias de experiências transexuais na escola. Para esta pesquisa, os sujeitos foram mulheres e homens transexuais e travestis. Conforme Santos (2012, p. 155), “as primeiras aproximações com as narrativas sobre a experiência escolar demonstraram que esta se constituiu por memórias traumáticas, na medida em que articulam dor, sofrimento e a reivindicação do reconhecimento do gênero".

No ano de 2013, a professora transexual Marina Reidel defendeu sua pesquisa de mestrado pelo Programa de Pós-Graduação em Educação (UFRGS), intitulada - A Pedagogia do Salto Alto: histórias de professoras transexuais e travestis na educação brasileira. Segundo Reidel (2013), o número de professores transexuais e travestis na educação brasileira é de, aproximadamente, sessenta profissionais. Apesar de ser um número baixo, comparado com o número de transexuais que exercem uma profissão que não seja a prostituição, podemos pensar que a escola, ainda que traumática, é um espaço buscado pelas trans e que há, inclusive, um grupo de reflexão entre educadores para tratar de suas questões. ${ }^{8}$ A autora destaca que as discriminações contra homossexuais, travestis e transexuais são praticadas pelos diferentes profissionais da educação e, às vezes, mesmo sem agir diretamente, os diferentes profissionais presentes na escola silenciam frente às ações discriminatórias produzidas por estudantes. Mesmo quando a discriminação parte apenas de alunos/as, a escola não se torna isenta, pois, "consentida e ensinada na escola, a homofobia se expressa pelo desprezo, pelo afastamento, pela imposição do ridículo" (LOURO, 1999, p. 29).

Segundo as pesquisas aqui enunciadas, tanto na região sul como no Brasil, de modo geral, a discriminação atinge as pessoas trans e a todos os segmentos LGBT e, por isso, ressaltamos que as evidências nos mostram que "a escola se nega a perceber e a reconhecer as diferenças entre alunos, mostrando-se 'indiferente ao diferente', em relação aos estudantes homossexuais, bissexuais ou transgêneros" (BONNEWITZ, 2003, p. 119). O corpo docente da escola costuma dirigir-se a seus grupos de estudantes como se não houvesse ali um gay, uma lésbica ou alguém que se interrogue acerca de suas práticas sexuais ou de seu gênero. Pelo fato de serem ignorados pela escola, poucos estudantes sentem-se à vontade com a exposição de seus corpos, e aqueles que se atrevem a mostrá-los são rejeitados e excluídos.

\footnotetext{
${ }^{8}$ Marina Reidel é coordenadora de um grupo que reflete sobre a condição de ser educadora e trans, a Rede de Educadoras Trans da Associação Nacional de Travestis e Transexuais (ANTRA). Rede TRANS EDUC. Disponível em: <http://tantasnoticiasx1.blogspot.com.br/2010/07/para-divulgacao-rede-trans-educ.html>. Acesso em: 18 jul. 2015.
} 
Tal fato estimula outros estudantes a utilizarem, também, a própria invisibilidade como estratégia de sobrevivência (BONNEWITZ, 2003).

Percebe-se que é como estudantes homossexuais que todos os alunos considerados diferentes tornam-se visíveis na escola, excluindo-se outras possibilidades como serem bissexuais, travestis, transexuais ou transgêneros. Ao mesmo tempo em que a escola rotula como gays os diferentes, ela oculta qualquer tipo de informação que possa motivar esses mesmos estudantes a se identificarem com qualquer outra identidade de gênero e de práticas sexuais. Os dados sobre a presença, em Santa Catarina, de estudantes com referências de gênero e de sexualidade que fogem ao padrão hegemônico são escassos, mais ainda em relação àqueles(as) que se autodefinem transexuais. Na educação, essa problemática ainda é pouco abordada por gestores das políticas públicas, de onde decorre a necessidade de estudos qualitativos, que façam conhecer e analisar os contextos educativos em que estão inseridas as pessoas transexuais. Ao falar de professoras, é possível verificar que, incluindo as duas transexuais entrevistadas, de acordo com Lirous K’yo Fonseca Ávila, coordenadora geral da Associação em Defesa dos Direitos Humanos com Enfoque na Sexualidade (ADEH) de Florianópolis [informação verbal], ${ }^{9}$ existem também seis outras profissionais autodefinidas transexuais que trabalham direta ou indiretamente com educação. Deste total de oito profissionais (aqui incluídas as professoras deste estudo), apenas duas não são ativistas de movimentos sociais ou de organizações não governamentais (ONG) ligadas ao movimento LGBT.

\section{EXPERIÊNCIAS ESCOLARES E A DISCRIMINAÇÃO}

A partir das experiências escolares de Jéssica e Carolina, foram elencados aspectos ligados a gênero e sexualidade no contexto escolar, bem como as relações professor versus estudante. Muitas dessas memórias e vivências expressam as discriminações sobre essas estudantes-professoras no ambiente escolar de sua época de alunas.

Valores e atitudes relacionados a gênero e sexualidade destinam-se a manter determinados grupos em posição de inferioridade em relação ao grupo que se considera representante do padrão binário hegemônico de sexualidade e de gênero. Para alguns

\footnotetext{
${ }^{9}$ Informação obtida por meio de conversa informal durante o levantamento inicial para a pesquisa.
} 
estudiosos, como Junqueira, essa discriminação tem o nome de homofobia e abarca todo segmento LGBT.

\begin{abstract}
Um conjunto de emoções negativas (tais como aversão, desprezo, ódio, desconfiança, desconforto ou medo), que costumam produzir ou vincular-se a preconceitos e mecanismos de discriminação e violência contra pessoas homossexuais, bissexuais e transgêneros (em especial, travestis e transexuais) e, mais genericamente, contra pessoas cuja expressão de gênero não se enquadra nos modelos hegemônicos de masculinidade e feminilidade. A homofobia, portanto, transcende a hostilidade e a violência contra LGBT e associa-se a pensamentos e estruturas hierarquizantes relativas a padrões relacionais e identitários de gênero, a um só tempo sexistas e heteronormativos (JUNQUEIRA, 2007, p. 60-61).
\end{abstract}

Entretanto, ao utilizarmos o termo homofobia como referência a todas as pessoas LGBT, corremos o risco de reforçar a visibilidade de pessoas trans como homossexuais, interpretando-as como gays que se vestem de mulher ou lésbicas que se vestem de homem. Com os novos dados sobre violência homofóbica na sociedade brasileira (BRASIL, 2012, 2013), em que se pode visualizar a violência contra diferentes expressões trans, o termo transfobia ganha centralidade devido à vulnerabilidade a que estão expostas as pessoas trans (CÉSAR, 2009). Berenice Bento ressalta a violência sobre a população trans:

Segundo a ONG Internacional Transgender Europe, o Brasil é o país onde mais ocorrem assassinatos de travestis e transexuais em todo o mundo. Entre janeiro de 2008 e abril de 2013, foram 486 mortes, quatro vezes a mais que no México, segundo país com mais casos registrados. Em 2013 foram 121 casos de travestis e transexuais assassinados em todo o Brasil. Mas estes dados estão subestimados. Todos os dias, via redes sociais, nos chegam notícias de jovens transexuais e travestis que são barbaramente torturadas e assassinadas (BENTO, 2014, p.1).

Segundo Bento, os dados do Brasil foram extraídos de publicações nos jornais brasileiros, que têm por prática divulgar em detalhes essas mortes. Por isso, o termo transfobia ganha relevância e contribui para denunciar quaisquer formas de discriminação direcionadas contra o modo como a pessoa trans exerce sua sexualidade, mas, principalmente, produz sua expressão de gênero em não conformidade com o esperado de seu sexo anatômico de nascimento.

\title{
3.1 Vivências como estudantes na Educação Básica
}


Em um primeiro momento, quando indagada sobre como viveu sua sexualidade como aluna na Educação Básica, ela nos faz pensar que a camuflagem que imaginava produzir não era bem sucedida e ao final, só lhe trazia sofrimento, conforme relato abaixo:

\section{[...] assistindo a esses bullying passando na TV, esse menino que teve esse problema que se matou no Rio de Janeiro. ${ }^{10} \mathrm{Se}$ eu for me remeter a minha história de vida, olha, eu sofri tanto, tanto, tanto na escola! $A$ escola foi para mim o ambiente mais negativo que você possa imaginar. Assim, todas as barbáries fizeram comigo, todas, todas. Eu tive que viver uma vida camuflada [se vestia de modo masculino e se via como homossexual na educação básica], uma vida mentirosa por um longo tempo (E. Carolina).}

Além disso, comparar sua vida com um assassinato coletivo poderia parecer um exagero, mas não o é, se pensarmos nas notícias de jornal a todo instante divulgando dados de assassinatos de pessoas trans por meio de morte violenta e das muitas transfobias relatadas nos trabalhos já citados de Peres (2009), Santos (2012) e Reidel (2013). Caminhando na indefinição com relação a como viam expressões de gênero e sexuais, ambas incorriam nos mesmos resultados que sofriam os demais segmentos da população LGBT. Por isso, o medo da reação de colegas e professores faz com que a escola se torne

[...] um dos espaços mais difíceis para que alguém "assuma" sua condição de homossexual ou bissexual. Com a suposição de que só pode haver um tipo de desejo e que esse tipo - inato a todos - deve ter como alvo um indivíduo do sexo oposto, a escola nega e ignora a homossexualidade (provavelmente nega porque ignora) e, desta forma, oferece muito poucas oportunidades para que adolescentes ou adultos assumam, sem culpa ou vergonha, seus desejos. O lugar do conhecimento mantémse, com relação à sexualidade, como lugar do desconhecimento e da ignorância (LOURO, 1999, p. 30).

Para a professora Jéssica, as relações com seus professores do Ensino Básico igualmente foram marcadas por constrangimentos quando se considerava gay, conforme nos relatou. De acordo com suas falas, a partir da antiga quinta série do Ensino Fundamental, suas

\footnotetext{
${ }^{10}$ Wellington Menezes de Oliveira, de 23 anos, invadiu uma escola no Rio de Janeiro armado com dois revólveres e atirou contra os alunos presentes, matando doze deles, com idade entre 12 e 14 anos. Não se sabe ao certo o motivo do crime, mas, na nota de suicídio de Wellington lia-se que ele era reservado, sofria bullying e pesquisava sobre terrorismo e fundamentalismo, conforme o relato de sua irmã adotiva e o de um colega próximo, (ESPECIAL FOLHA UOL, Massacre do Realengo. [ONLINE] 7 abr. 2011 Disponível em: <http://www1.folha.uol.com.br/especial/2011/tragediaemescolanorio/>. Acesso em: 20 fev. 2014.
} 
maiores dificuldades eram com professores homens, que ironizavam seus trejeitos e suas atitudes.

Tinha professor que dizia aquela coisa bem idiota: isso não é completamente menino, te comporta como homem, menino tem que andar com menino! [...] que eu só andava com meninas. Assim, minha vida inteira passei ouvindo "bichinha", aquelas coisas que tu sempre ouve, qualquer gay ouve ( $E$. Jéssica).

Antes da discriminação transfóbica, esses sujeitos vivenciavam a homofobia no controle de seus corpos, o mesmo tempo em que viviam a crítica à feminilidade que de algum modo expressavam. E foi durante as aulas de Educação Física, quando esse corpo se revelava fora dos padrões esperados, que as tensões aumentavam, e os conflitos decorrentes de discriminações pareciam ultrapassar o grau mínimo de liberdade individual. O desprazer das aulas de Educação Física fazia parte do cotidiano das entrevistadas.

Minha tortura era Educação Física, foi a tortura da tortura da tortura. Olha, se tem uma disciplina que pode riscar do mapa para mim é Educação Física! [risos] [...] Mas assim, eu não gostava de me expor, e eu sou péssima em esportes, então, eu ficava muito envergonhada. Jogar vôlei para mim era uma tortura. Futebol mesmo, nem pensar [...] era bem complicado! (E. Jéssica).

Educação Física era unânime. Porque Educação Física, na minha época, [década de 1970] era separado, meninos e meninas. Ai, tu imagina! Jogar futebol eu não conseguia jogar de jeito nenhum, não é porque a gente é fresco não, é porque tu não se identifica. Porque eu também não acho nada demais você ser uma trans e jogar futebol. [...] mas eu não gostava, não era o que eu queria, mas eu era forçada, e aí botavam para ir no gol. Aí tu imagina, piorou, ainda, porque cada vez que a bola vinha, eu virava de costa porque eu tinha medo que a bola me machucasse, [...] e eles caíam de pau em cima de mim (E. Carolina).

Para Carolina, a obrigação de ser goleira sem querer e ainda não ser considerada uma boa goleira, apenas a expunha às críticas dos demais, fragilizando-a. Como afirma Helder Guerra de Resende (1994, p. 24), “as aulas de Educação Física encontram-se repletas de conflitos inerentes a qualquer forma de interação social, que precisam ser mediados pela intervenção acadêmica e social do professor". Podemos acrescentar que a 
heteronormatividade masculina presente na sociabilidade do futebol, e que é demonstrada por professores e alunos, agudizam esses conflitos. No resgate histórico sobre as masculinidades presentes entre os professores de Educação Física nas últimas décadas, e que ainda persiste em muitas escolas o futebol, figurava e ainda figura como uma das expressões de masculinidade mais determinantes (SOMARIVA, 2015).

Mas, no caso de Carolina, além da cultura heteronormativa priorizar os conteúdos curriculares de futebol para os meninos, parece ter havido também heterossexismo, já que a pressão para que jogasse futebol ganhava ares de punição, porque, se ela não reivindicava futebol, a obrigavam a ser goleira, mas quando reivindicava vôlei, não a colocavam, mesmo havendo um time masculino, como ela mesma descreveu: "Vamos supor - vôlei - eu podia estar jogando vôlei. Porque eu tinha essa habilidade, eu gostava. Só que não, eles não me colocavam no time, que era o time masculino.” (E. Carolina).

Jéssica, ao contrário de Carolina, por não gostar das aulas de Educação Física e se considerar sem habilidades para atividades físicas, relatou piadas e insultos nas aulas, e utilizou como estratégia o afastamento para praticar xadrez. Contudo, além dos esportes, outras disciplinas escolares também expressavam a heteronormatividade, não permitindo a demonstração de outras habilidades de estudantes, como no caso de artes, conforme relato de Carolina: [...] Eles poderiam ter me explorado nisso, como teatro. Na verdade, eu poderia ter feito uma peça que eu tivesse uma identidade de gênero feminina, mas não - porque "ah, como um homem vai se vestir com roupa de mulher?".

Aqui é possível pensar, com Corinta Geraldi (1994), sobre o desenvolvimento concreto do currículo nas situações cotidianas formais e informais dentro e fora da sala de aula, que define como currículo em ação aquilo que "ocorre de fato nas situações típicas e contraditórias vividas pelas escolas, com suas implicações e compreensões subjacentes, e não o que era desejável que ocorresse e/ou o que era institucionalmente prescrito" (1994, p. 117). Nos currículos de arte, por exemplo, não há nada que torne impossível a troca de personagens em função do sexo de nascimento, da sexualidade ou do gênero de estudantes, no entanto isso parece não ser praticado na medida em que a escola, em conjunto com outras instituições sociais, participa também da produção da heteronormatividade. Aliás, os conteúdos presentes nos temas transversais dos Parâmetros Curriculares Nacionais, principalmente no volume que trata das questões de gênero e sexualidade (BRASIL, 1997) dizem o contrário, que deveriam ser inseridos no planejamento de todas as disciplinas. Esse currículo vivido que não só 
dificulta, mas dissocia, as experiências relacionais das de outras áreas, limita o aprendizado não tanto de estudantes trans como dos demais, na medida em que poderia contribuir para a ampliação da capacidade relacional e criativa de todos/as. Carolina demonstrou ressentir-se desses obstáculos:

[...] em todo momento eu fui abafada [...] Na verdade, nessa época, eles não deixaram eu ser quem eu realmente era. Eu tenho certeza e conviç̧ão que eu fui abafada, que eu poderia ser uma pessoa, me tornado uma pessoa muito mais [fala inaudivel] muito melhor. Eu tenho certeza, a palavra seria muito melhor, se naquela época eu trabalhasse melhor comigo mesmo.

De modo geral, a desconsideração pelas particularidades dessas estudantes trans e a preocupação com a formação integral em suas múltiplas necessidades persiste na formação de professores e pode provocar o abandono escolar. Um dos reflexos deste alto índice de violência escolar contra travestis e transexuais é a evasão, como no caso relatado pela pesquisa de Bohm (2009), em que 35\% das entrevistadas alegaram ter abandonado a escola por conta das violências dirigidas a elas. Situação, no entanto, evitada por Carolina, que resistia aos maus-tratos.

Eu sempre dei a volta por cima e nunca deixei as pessoas tomar, não. Nunca eles [colegas, professores] tiraram, não. Eu sempre revidei. Se me atirassem uma pedra, eu atirava duas. [...] eu fui muito forte, sinceridade. Então, assim, eu sempre fui ousada, sempre bati boca com o professor, até na própria faculdade ( $E$. Carolina, grifos nossos).

Os sentidos das palavras tomaram e tiraram parecem remeter ao universo simbólico da negação e resistência: eles não a aceitavam como ela era, mas, ainda assim ela resistia, revidava. A reafirmação de si conta a homofobia/transfobia expressas pela hostilidade do meio escolar denunciam as contradições cotidianas da subalternidade ocupada pelas pessoas trans. Durante todo o Ensino Básico, Carolina foi rotulada como gay e discriminada: "Queira ou não queira os professores me chamavam de veado, os professores me taxavam, os professores me excluíam, as pessoas me excluíam e a escola volta e meia me chamava para 
discutir o meu comportamento" (E. Carolina). E era seu comportamento o que se considerava problema, e não a discriminação contra ela.

No entanto, mesmo com todas as intervenções negativas, ambas conseguiram resistir e seguir em seus estudos nas licenciaturas de Letras e de História.

\subsection{Vivências como estudantes na universidade}

Se mais fortalecidas pelos embates das experiências escolares na educação básica, a entrada na graduação provocou mudanças decisivas de transformação e autoconhecimento, tanto para Carolina quanto para Jéssica. Destacamos, nesse período, a continuidade da não aceitação social combinada com a resistência por meio da forte interação com uma parcela de colegas e professores universitários e a persistência de embates diretos contra o heterossexismo. $^{11}$

Algumas evidências foram relatadas sobre o processo de negação que persistia. Quando, já na faculdade, Jéssica iniciou a mudança do modo de se vestir e passou a ter uma aparência de gênero mais feminina, a curiosidade de colegas e a exclusão acompanharam esse momento.

\section{[...] eles achavam que eu era louca, que eu tinha problema mental. Chegou uma colega minha dizer que um colega comentou que eu tinha problema mental. Isso para um estudante de História! Me indignei. Eu notava, todos são convidados para aquela festa, menos tu. Eu sentia isso! (E. Jéssica).}

Na universidade, a sociabilidade de Jéssica limitava-se ao pequeno grupo de algumas colegas que estudavam com ela, pois temia que os homens interpretassem sua aproximação como interesse sexual ou afetivo.

Sempre fui tímida. Na faculdade era engraçado. Eu, no meu grupo, eu era um ser, quando elas faltavam, [eu] era um outro completamente diferente. Ficava quieta, no meu canto, não olhava para o lado. Quando eu estava no meu grupo eu falava, ria,

\footnotetext{
${ }^{11}$ No momento da elaboração dessa pesquisa não encontramos estudos sobre a temática da transexualidade nas universidades, o que nos dificultou comparações com outros contextos acadêmicos.
} 
conversava. Era meu porto seguro, o meu [ênfase] grupo (E. Jéssica).

Nas histórias relatadas por Jéssica, a transfobia parecia vir predominantemente dos homens, mas não vinha apenas daqueles considerados masculinos e heterossexuais: professores considerados gays pelos demais, mas que não afirmavam publicamente exercer esta prática sexual também a discriminavam. ${ }^{12}$

Era bem quando eu estava começando a transformação, e ele [professor] pegou, relatou o fato dele no carnaval no Rio de Janeiro, que viu um travesti que tinha colocado silicone na bochecha e que, com 70 anos, aquilo estava caindo e parecia uma aberração. Parecia que todo mundo olhou para mim e que ele falou, olhando para mim, como quem dizia: "tu queres continuar isso? tu vais ficar assim!" (E. Jéssica).

Naquele momento em que produziam novas transformações corporais e de modos de vestir, sofriam o estigma de estranho, de aberração. A veracidade ou não sobre as práticas sexuais desse professor não importa de fato, já que esse tipo de ocorrência é comum em nossa sociedade, tendo sido analisado por outros autores (BARBERO, 2003). Porém, um aspecto que nos chamou a atenção é que em cursos de formação de professores (Letras e História) -no caso de Carolina, durante o período ditadura militar em finais da década de 1970, e no caso de Jéssica, os anos 1990, com a força dos movimentos sociais-, o currículo em ação guardava fortes semelhanças entre si com relação aos padrões binários hegemônicos.

Carolina, que passou a se apresentar como travesti assim que entrou na graduação, afirmou que um colega de faculdade não participava da mesma equipe de trabalho porque "ele mesmo fazia questão de falar que não estudava comigo porque eu era uma aberração, estar vestida daquele jeito!” (E. Carolina). Lembrou-se também de outra cena transfóbica:

Nós, no primeiro dia já, ele [professor] pediu pra gente fazer um título, [...] ele veio e brincou, falando que eu tinha colocado flor, já para me excluir. Aí, lógico que todo mundo ri. Aí eu peguei, revidei, e todo mundo riu também. Disse que eu fiz flor pensando nele. Até umas gurias chamaram [a Carolina] e [disseram]- "não faz isso, porque ele persegue e depois ele te reprova". Eu disse: Eu, hein,

\footnotetext{
${ }^{12}$ Ela não se lembra de algum momento em que esses professores assumiram publicamente que tinham qualquer tipo de práticas sexuais com outros homens, mas sim do que a turma de estudantes comentava.
} 
querida! Pode me reprovar, mas eu não vou deixar barato, não! (E. Carolina).

O assédio que visava reforçar a normatividade binária colocou à prova a estudante já no seu primeiro dia de aula. Como se pode analisar, a luta contra a evasão escolar é cotidiana e árdua, e a ironia de Carolina parecia ser um dos recursos frente à transfobia.

Outro aspecto de tensão relacionava-se à polêmica de uso do nome de registro ou nome social, tão presente nos debates no início do século XXI, também relatada por Jéssica na universidade em final dos anos 2000, quando cursava a quinta fase. Naquele momento, quando já se identificava como transexual feminina, sentia-se constrangida toda vez que o professor, no momento da chamada, utilizava do nome masculino de registro para chamá-la.

\begin{abstract}
No momento que eu me sentia à vontade, foi quando eu estava vestida de mulher em sala de aula. [...] Mas era estranho porque eu vestia roupa de mulher e dai era horrivel na chamada chamar meu nome de registro, era horrivel, horrivel... Eu queria me matar na hora da chamada, [...] mas tinha professor que tinha prazer em fazer e ainda olhava com aquele olhar estranho. [...] Em nenhum momento um professor chegou para mim e perguntou: "tu queres ser tratada como? [...] Tu queres ser tratada como menina, é isso que tu queres realmente?" Ninguém me questionou! [Pesquisador: E você não tinha coragem em pedir isso?] Porque também, o único professor que eu pedi abertura foi a Carla, que eu pedi para botar na chamada "Jéssica", daí ela toda, sempre foi Jéssica para ela (E. Jéssica).13
\end{abstract}

A designação pelo nome de nascimento quando se opta por um nome social constituise como violência simbólica e está na pauta diária dos movimentos LGBT. Afinal, é por meio do nome que, em nossa sociedade, um sujeito expressa seu pertencimento de sexo e de gênero, e até mesmo gera uma imagem pública sobre a sua sexualidade. Em nossa cultura os nomes também correspondem a padrões binários muito demarcados em relação ao gênero, e esse é mais um problema para a expressão dos sujeitos trans. Para Santos (2012, p. 157), "o nome proporciona também meios de classificar, categorizar, agrupar por semelhanças, opor e comparar grupos pelas diferenças.”. Esta autora analisa que, na escola, “o nome representa a

\footnotetext{
${ }^{13}$ Carla é um nome fictício, alterado aqui para preservar o anonimato da pessoa citada.
} 
diferença entre a permanência ou não na instituição" (p. 158), e descreve as narrativas de seus sujeitos entrevistados quando falam da dor de não serem aceitos em seus nomes sociais.

Como parte dessa luta pelo nome social, o Grupo Dignidade (2015), organização não governamental sediada em Curitiba, compilou 12 resoluções das 24 universidades que afirmam ter incluído a resolução, sendo elas: UFG, UFBA, UFRJ, UFRG, UFMS, UFRN, UFVSF, UFF, UFABC, UNIPAMPA, UFES e UFSC. ${ }^{14}$ Por meio dessas ações de acompanhamento, entre outras, o movimento tem lutado para que todas as universidades implementem a Resolução nº12 de 16 de janeiro de 2015 (BRASIL, 2015, p. 1) que

estabelece parâmetro para a garantia das condições de acesso e permanência de pessoas travestis e transexuais - e todas aquelas que tenham sua identidade de gênero não reconhecida em diferentes espaços sociais - nos sistemas e instituições de ensino, formulando orientações quanto ao reconhecimento institucional da identidade de gênero e sua operacionalização.

No início dos anos 2000 certamente era muito difícil reivindicar esses direitos na universidade, mas se compararmos os espaços e discriminações nos diferentes ambientes escolares, é possível supor que a universidade tenha sido mais sutil, mas não menos discriminatória na relação com colegas e professores, talvez pelas transexuais expressarem mais firmeza e cuidado em suas relações sociais, fruto do árduo aprendizado escolar e social anterior. Contudo, ainda faltam pesquisas para dialogar sobre essa problemática nas experiências de Educação Superior.

\section{CONSIDERAÇÕES FINAIS}

Podemos pensar o quanto estão imbricadas as questões pedagógicas e as questões socioculturais de estudantes nas histórias aqui registradas e analisadas: experiências relacionais e também de desenvolvimento de conteúdos se mesclam nos relatos, bem como as pressões a que resistiram, evitando a evasão escolar e a persistência que as fez professoras e a voltar para esse ambiente tão excludente. Destacamos que a pouca preocupação de professores com as questões de gênero e de sexualidade ou, mais do que isso, o

\footnotetext{
${ }^{14}$ GRUPO DIGNIDADE: Nome social para Travestis e Transexuais já é realidade em 24 Universidades/Faculdades Brasil. Disponível em: <http://www.grupodignidade.org.br/blog/2015/nome-socialpara-travestis-e-transexuais-ja-e-realidade-em-24-universidades-faculdades-brasil/>. Acesso em: 10 jul. 2015.
} 
heterossexismo presente, não só contribuiu negativamente para a constituição do sujeito em sua subjetividade amorosa e sexual, como interferiu/bloqueou a ação escolar em seu papel de mediadora no acesso ao conhecimento e à sociabilidade que nos faz sentir o pertencimento ao gênero humano.

Como professoras, ambas trazem as marcas desse passado de alunas e refletem sobre ele. Carolina, que considera a transexualidade uma bandeira política, tenta transformar a negatividade em positividade e busca imprimir, na escola onde atua, as discussões que vivencia no movimento LGBT. Por sua vez, Jéssica, que não se vê como ativista, lamenta o preconceito presente nas pessoas e que persiste a cada escola em que atua, onde sempre vê sua imagem aprisionada à condição de travestilidade.

Assim ó, o que mais me decepcionou e me decepciona, que mais me deixa magoada, [por] mais que eu dou o melhor de mim, faço o que eu posso, eu sempre tento inovar: eu sei que eu vou ser lembrada como uma travesti, a travesti que dava História. Isso é o que mais me decepciona![aparenta ficar emocionada nesse momento] ( $E$. Jéssica).

O estigma impõe sofrimento e Jéssica insurge-se contra essa categorização em primeiro plano, como fundante, que se dá através da prática sexual de uma pessoa, ainda tão comum nos séculos XX e XXI (FOUCAULT, 1984), ao contrário do que desejaria, ser vista como uma boa professora de história. A densidade dos relatos dessas estudantes-professoras nos mostra que a presença de sujeitos com expressões de gênero e sexualidade fora dos padrões binários desestabiliza o ambiente escolar. Por tudo isso, verificamos que estamos longe de produzir um espaço escolar que envolva o reconhecimento dos direitos à liberdade de gênero e de práticas sexuais, assim como questionamos a qualidade desses currículos heteronormativos que acompanham crianças e jovens, e que depois são ofertados como formação inicial de professores/as, recriando o velho sob novas vestes.

\title{
SCHOOL EXPERIENCES OF TRANS STUDENTS
}

\author{
Abstract


This investigation aims at reclaiming memories of two self-defined female transsexuals from Tubarão - SC, in their school days, in order to analyze their school experiences during their gradual feminization process. It is a qualitative research, built with cutouts of their life stories during their primary and secondary education in public schools and degrees in History and Letters at private universities. The empirical research took place from interviews through a semi-structured questionnaire, and analyzed based on the assumptions of gender and education studies. The contradictory school space showed to be a place of heterosexist discrimination, attentive against those who did not fit the binary and hegemonic patterns of gender and sexuality. However, due to the support of colleagues and the resistance of the transsexual students, such context did not prevent them from continuing in their studies.

Keywords: Gender; Sexuality; Transsexuality; School Experience

\section{EXPERIENCIAS ESCOLARES DE ESTUDIANTES TRANS}

\section{Resumen}

Este estudio trata de recuperar la memoria de dos auto-definidas transexuales femeninas, de la ciudad de Tubarão - SC, durante sus años escolares, con el fin de analizar sus experiencias en la escuela durante su gradual proceso de feminización. Se trata de una investigación cualitativa, construida con recortes de sus historias de vida en la educación básica en escuelas públicas y los grados de Historia y Letras en universidades privadas. La investigación empírica se llevó a cabo a partir de entrevistas con guión semiestructurado, y se analiza en base a los presupuestos de los estudios de género y la educación. El contradictorio espacio escolar se presentó como un lugar de discriminación heterosexista, vigilante contra los que no se ajustasen a los patrones binarios y hegemónicos de género y de sexualidad. Sin embargo, debido al apoyo de las colegas y la resistencia de las estudiantes transexuales, tal contexto no les impidió de continuar sus estudios.

Palabras Clave: Género; Sexualidad; Transexualidad; Experiencia Escolar

\section{REFERÊNCIAS}


BARBERO, Graciela Haydée. Homossexualidade e identidades diversas: O preconceito que as acompanha. Pulsional Revista de Psicanálise, São Paulo, Centro de Psicanálise, n. 170, p. 27-36, jun. 2003.

BARBOSA, Bruno Cesar. Nomes e diferenças: Uma etnografia dos usos das categorias travesti e transexual. 2010.130 f. Dissertação (Mestrado em Antropologia) - Faculdade de Filosofia, Letras e Ciências Humanas. Universidade de São Paulo, São Paulo, 2010.

BENEDETTI, Marcos Renato. Toda Feita: o corpo e o gênero das travestis. Rio de Janeiro: Garamond, 2005.

BENTO, Berenice. O que é transexualidade?. São Paulo: Brasiliense, 2008.

BENTO, Berenice. Brasil: País do transfeminicídio. Centro latino-americano em sexualidade e direitos humanos - CLAM. 2p. Portal Fórum. 9 jun.2014. Disponível:

http://www.revistaforum.com.br/2014/06/09/brasil-o-pais-transfeminicidio/. Acesso em $26 \mathrm{de}$ Jan. 2016.

BOHM, Alessandra Maria. Os monstros e a escola: identidade e escolaridade de sujeitos travestis. 2009. 91f. Dissertação (Mestrado em Educação) - Faculdade de Educação, Universidade Federal do Rio Grande do Sul, Porto Alegre, 2009.

BONNEWITZ, Patrice. Primeiras lições sobre a sociologia de P. Bourdieu. Tradução Lucy Magalhães. Petrópolis: Vozes, 2003.

BORRILLO, Daniel. A Homofobia. In: LIONÇO, Tatiana; DINIZ, Débora. (Org.). Homofobia e Educação: um desafio ao silêncio. Brasília: Editora UnB, 2009. P.15-46.

BRASIL. Secretaria de Educação Fundamental. Parâmetros Curriculares Nacionais: Pluralidade cultural, Orientação sexual. Secretaria de Educação Fundamental. V.10. Brasília: MEC/SEF, 1997.

BRASIL. Secretaria de Direitos Humanos. Relatório sobre violência homofóbica no Brasil: ano de 2011. Brasília: 2012. 138 p. Disponível em: <http://www.abglt.org.br/docs/RelatorioLGBT_SDH.pdf>. Acesso em: 20 de Jun. 2014.

BRASIL. Secretaria de Direitos Humanos. $2^{\circ}$ Relatório sobre violência homofóbica no Brasil: ano de 2012. Brasília: 2013. 101 p. Disponível em:

<http://www.sdh.gov.br/assuntos/lgbt/pdf/relatorio-violencia-homofobica-ano-2012>. Acesso em: 20 de Jun. 2014.

BRASIL. Secretaria de Direitos Humanos. Resolução $N^{o} 12$, de 16 de janeiro de 2015. Brasília: 2015. 2 p. Disponível em: <http://www.sdh.gov.br/sobre/participacao-social/cncdlgbt/resolucoes/resolucao-012>. Acesso em: 22 de Jul. 2015. 
CARRARA, S.; RAMOS, S.. Política, direitos, violência e homossexualidade: Pesquisa $9^{\mathrm{a}}$ Parada do Orgulho GLBT - Rio 2004. Rio de Janeiro: Cepesc, 2005.

CÉSAR, Maria Rita de Assis. Um nome próprio: transexuais e travestis nas escolas brasileiras. In: REUNIÃO ANUAL DA ASSOCIAÇÃO NACIONAL DE PÓSGRADUAÇÃO E PESQUISA EM EDUCAÇÃO, 32., 2009, Caxambu. Anais eletrônicos... Rio de Janeiro: ANPED, 2009. 14 p. Disponível em: <http://32reuniao.anped.org.br/arquivos/trabalhos/GT23-5521--Int.pdf>. Acesso em: 20 de Fev. 2014.

ESPECIAL FOLHA UOL. Massacre do Realengo. [ONLINE] 7 abr. 2011. Disponível em: <http://www1.folha.uol.com.br/especial/2011/tragediaemescolanorio/>. Acesso em: $20 \mathrm{de}$ Fev. 2014.

FOUCAULT, Michel. História da sexualidade I: A vontade de saber. Tradução Maria Thereza da Costa Albuquerque. 9ªed. Rio de Janeiro: Graal, 1984.

GERALDI, Corinta Maria Grisola. Currículo em ação: buscando a compreensão do cotidiano da escola básica. Pro-posições, Campinas, v. 5, n. 3 [15], p.111-132, Nov. 1994.

GRUPO DIGNIDADE. Nome social para Travestis e Transexuais já é realidade em 24 Universidades/ Faculdades Brasil. Disponível em:

<http://www.grupodignidade.org.br/blog/2015/nome-social-para-travestis-e-transexuais-ja-erealidade-em-24-universidades-faculdades-brasil/> . Acesso em 22 de Jul. 2015.

JUNQUEIRA, Rogério Diniz. (Org.). Diversidade Sexual na Educação: problematizações sobre a homofobia nas escolas. V.32. Brasília: Ministério da Educação, Unesco, 2009.

JUNQUEIRA, Rogério Diniz. O reconhecimento da diversidade sexual e a problematização da homofobia no contex to escolar. In: RIBEIRO, Paula Regina Costa; SOUZA, Nádia Geisa Silveira de; GOELLNER, Silvana Vilodre; SOUZA, Josué Ferreira. (Org.). Corpo, gênero e sexualidade: discutindo práticas educativas. Rio Grande: Editora da FURG, 2007. P. 59-69.

LAQUEUR, Thomas Walter. Inventando o sexo: corpo e gênero dos gregos a Freud. Tradução Vera Whately. Rio de Janeiro: Relume-Dumará, 2001.

LOURO, Guacira Lopes. Corpos que escapam. Labrys: estudos feministas. Brasília, n. 4, p. 111, ago./dez. 2003. Disponível em: <http://www.labrys.net.br/labrys4/textos/guacira1.htm>. Acesso em: 20 de Fev. 2014.

LOURO, Guacira. Pedagogias da sexualidade. In: LOURO, Guacira Lopes. (Org.). O corpo educado: pedagogias da sexualidade. Belo Horizonte: Autêntica, 1999. P. 7-35.

PERES, William Siqueira. Cenas de exclusões anunciadas: travestis, transexuais, transgêneros e a escola brasileira. In: JUNQUEIRA, Rogério Diniz. (Org.). Diversidade sexual na educação: problematizações sobre a homofobia nas escolas. v.32. Brasília: Ministério da Educação, Unesco, 2009, P. 235-263. 
REIDEL, Marina. Pedagogia do salto alto: histórias de travestis e transexuais na Educação Brasileira. 2013. 147 f. Dissertação (Mestrado em Educação) - Faculdade de Educação, Universidade Federal do Rio Grande do Sul, Porto Alegre, 2013.

RESENDE, Helder Guerra de. Tendências pedagógicas da Educação Física Escolar. In: RESENDE, Helder Guerra de; VOTRE, Sebastião Josué. (Org.) Ensaios sobre Educação Física, Esportes e Lazer. Rio de Janeiro: SBDEF,1994. P.11-40.

SANTOS, Dayana Bruneto Carlin. Cartografias da transexualidade: a experiência escolar e outras tramas. 2012. 210 f. Dissertação (Mestrado em Educação) - Faculdade de Educação. Universidade Federal do Paraná, Curitiba, 2012.

SOMARIVA, João Fabricio Guimara. A prática pedagógica do futebol nas aulas de educação física sob uma perspectiva de gênero. 2015. 106 f. Dissertação (Mestrado em Educação) Faculdade de Educação. Universidade do Sul de Santa Catarina, Tubarão, 2015.

TORRES, M. A.; PRADO, M. A.. Professoras Transexuais e Travestis no Contexto Escolar: entre estabelecidos e outsiders. Educação \& Realidade, Porto Alegre. v.39, n. 1, p. 201-220, jan./mar. 2014. Disponível em: http://seer.ufrgs.br/index.php/educacaoerealidade/article/view/29664 . Acesso em: 22 de Jul. 2015.

Data de recebimento: 01/02/2016

Data de aceite: 07/03/2016 